\title{
Effect of Oral Erythropoietin in Prevention of Anemia of Prematurity
}

\author{
MD. JAMSHED ALAM ${ }^{1}$, MD. KAMRUL AHSAN KHAN ${ }^{2}$, NAZMUN NAHAR ${ }^{3}$, SANJOY KUMER DEY ${ }^{4}$, \\ MD. A. MANNAN ${ }^{5}$, MOHAMMOD SHAHIDULLAH ${ }^{6}$
}

\begin{abstract}
Introduction: Anemia of prematurity $(A O P)$ is a common problem of very low birth weight babies. Blood transfusion is a necessity when it occurs in moderate to severe form putting the child in to the risk of transfusion related complications. Erythropoietin, a potent stimulator of hemopoesis is available in breast milk in good amount and absorbed intact under physiologic condition. In this background oral recombinant human erythropoietin (rhEPO) can be a useful alternative to its subcutaneous administration in prevention of $A O P$.

Objective: To evaluate the efficacy of oral rhEPO in the prevention of AOP in very low birth weight (VLBW) neonates.

Methods: This randomized controlled study conducted in the NICU of BSMMU over one year. Total 60 preterm $(<34$ weeks)VLBW $(<1500 g)$ infants were enrolled and randomly divided into Control (group-I), Oral (group-II) and Subcutaneous (group III). Experimental groups (group-II \& group-III) received rhEPO 400 IU/Kg, 3 times weekly in oral and subcutaneous (S/C) route respectively and continued for 2 weeks (Total 6 doses). Therapy was initiated 14 days after birth when the baby achieved oral feeding of at least $50 \mathrm{ml} / \mathrm{kg} /$ day of breast milk. All infants received oral iron and folic acid supplementation up to 12 weeks of postnatal age. Transfusion data were recorded. Anthropometric and hematological assessments were done at 2, 4, 6 and 12 weeks of age.

Results: Baseline clinical characteristics and hematological values were almost similar in all groups. Mean hemoglobin were $11.34 \pm 0.68 \mathrm{gm} / \mathrm{dl}, 11.88 \pm 0.54 \mathrm{gm} / \mathrm{dl} \& 12.12 \pm 1.32$ $\mathrm{gm} / \mathrm{dl}$, the mean hematocrit were $34.11 \pm 2.03 \%$, 35.66 $\pm 1.65 \%$ \& $36.38 \pm 3.97 \%$ and the mean reticulocyte were $7.56 \pm 2.48 \%, 9.85 \pm 1.50 \%$ \& $9.22 \pm 3.11 \%$ in the control, oral and subcutaneous group respectively and the differences are statistically significant $(p<0.05)$. Weight gain was higher in the intervention group at 6 and 12 weeks follow up than the control group $(p<0.05)$. Only $2(5.25 \%)$ infants, one in each of the intervention groups required blood transfusion, compared to $6(31.5 \%)$ infants in control group $(p<0.01)$.
\end{abstract}

Conclusion: Oral EPO is as good as subcutaneous use of EPO in stimulating erythropoesis, maintaining HCT and Hb at high level and is safe in preterm baby.

Key words: Preterm very low birth weight, Anemia of prematurity, oral rhEPO.

1. Assistant Professor (Pediatrics), Sheikh Hasina Medical College, Tangail.

2. Assistant Professor (Neonatology), Sheikh Sayera Khatun Medical College, Gopalgonj.

3. Assistant Professor (Neonatology), MH Samorita Hospital \& Medical College, Dhaka.

4. Associate Professor (Neonatology), BSMMU, Dhaka

5. Professor \& Chairman. Dept. of Neonatology, BSMMU, Dhaka

6. Professor of Neonatology \& Ex. Pro VC. BSMMU, Dhaka

Correspondence: Dr. Md. Jamshed Alam, Assistant Professor (Pediatrics), Sheikh Hasina Medical College, Tangail. Mobile: 01730797504, E-mail: jalampc@gmail.com

Received: 26 January 2017

Accepted: 17 May 2017

\section{Introduction:}

Anemia in neonates is defined as more than 2 SD below the mean value of the amount of hemoglobin or HCT for a given age. ${ }^{1}$ It is very common in very low birth weight (VLBW) infant. ${ }^{2}$ Anemia of prematurity $(\mathrm{AOP})$ is a hyporegenerative anemia usually appearing after the second week, reaching its highest intensity in the second month of life. It is normocytic and normochromic anemia with a low reticulocyte count and has been attributed to erythropoietin (EPO) deficiency. The pathogenesis of AOP is not fully 
elucidated but contributory factors include the reduced life span of the fetal erythrocytes, the relatively low EPO concentration and rapid body growth. ${ }^{3}$ It has sometimes has clinical manifestations like pallor, tachycardia, tachypnea, apnea, decreased activity, no weight gain that necessitates blood transfusion. ${ }^{1,4}$ The mainstay of management of AOP is blood transfusion but it is not without the risk of transfusion transmitted infections, volume overload, alloimmunization etc. ${ }^{5}$ So reduction of blood transfusion in the treatment of AOP is always desired.

EPOis the major factor in erythropoiesis in the fetal and neonatal period as well as in puberty by inhibition of apoptosis of progenitors in erythroid lineage and provoking their proliferation and differentiation to normoblasts. ${ }^{6}$ Serum level of EPO in premature neonates is lower than mature neonates and after birth its level decreases even more. ${ }^{7}$ The low EPO levels detected in premature infants and proper response to synthetic erythropoietin suggested that EPO administration in premature infants could be of benefit in trying to maintain or increase the hematocrit levels. Studies showed that the severity of AOP and the need for red cell transfusion can be reduced by a combination therapy of recombinant human erythropoietin (rhEPO), iron and folic acid and by limiting iatrogenic blood loss. ${ }^{8,9,10}$ As therapy with rhEPO is found to be effective in the prevention of AOP, its use is increasing gradually. However, the optimal therapeutic dosage, duration, time and route of administration of rhEPO arestill remaining uncertain. A wide range of rhEPO doses and administration schedules have been evaluated in preterm infants since the first pilot study. ${ }^{11}$ Though the dose and administration schedules were variable but the results were almost similar.

EPO does not cross the placenta. EPO found in mother's milk, is produced by mammary glands. ${ }^{12,13}$ Evidence shows important developmental roles for these milk-borne growth factors. A significant proportion of milk-borne EPO resists proteolytic degradation. EPO receptors have been found on gastric and intestinal mucosa, and in mesenteric vascular endothelium. It has also been observed that the level of rhEPO, added to mother's milk or standard formula milk under conditions similar to that of the stomach or intestine remaining constant, but undergoes digestion when added to $5 \%$ dextrose or saline. ${ }^{14,15,16}$,

While parenteral rhEPO has been shown to enhance erythropoiesis and decrease the need for late blood transfusion in preterm infant, its enteral administration provided some conflicting results. ${ }^{13}$ One study showed increased erythropoiesis without any change in blood transfusion rate. ${ }^{1,17}$ In our study, we have compared the effectiveness of oral rhEPO versus subcutaneous rhEPO with control in prevention of AOP. Iron and folic acid supplementation was received by three groups. So far to our knowledge, no such study has yet been conducted in Bangladesh to evaluate the efficacy of oral Erythropoietin in prevention of AOP and to compare with injectable EPO and placebo. We have evaluated a simple and more suitable way for prevention of anemia of prematurity.

\section{Methodology:}

This randomized control trial (RCT) has been carried out in the Department of Neonatology of Bangabandhu Sheikh Mujib Medical University (BSMMU), over a period of one year from February 2013 to January 2014 after taking ethical clearance from the institute. Calculated sample size was 73 but a total of 60 newborn have been enrolled purposively. Newborn babies admitted in the NICU of BSMMU were the study population. Babies with gestational age $<34$ weeks, having birth weight $<1500 \mathrm{gm}$, with stable cardiopulmonary status and oral feeding has been started with breast milk and an amount of at least 50 $\mathrm{ml} / \mathrm{kg} /$ day is achieved, has been included. ${ }^{5}$ Infants with congenital anomalies, intra-ventricular hemorrhage, neonatal seizures, immune-mediated hemolytic anemia or having evidence of acquired or congenital infection or babies requiring ventilator support were excluded. After enrollment of each newborn, group allocation was done with sealed envelope method in to three groups' 20 each. Placebo is labeled as group-I, Oral erythropoietin Group-II and Subcutaneous erythropoietin as Group-III. Before randomization neither the parents nor the study physician were aware of the group the baby belongs.

After enrollment detailed history of each patient was taken from nearest/close relative to the mother. Then babies were examined thoroughly. Gestational age was determined by maternal record (Maternal recall of LMP or available ultra-sound reports) and further confirmed by New Ballard Scoring system. All relevant information was recorded in the predesigned questionnaire. Before intervention weight was measured by an electronic weighing scale (SALTER Model- 914 UK) with accuracy of $\pm 5 g$, keeping the baby undressed and before feeding by the neonatal nurse. OFC was measured with an inelastic standard plastic measuring tape to the nearest $1 \mathrm{~mm}$. Head circumference is the maximum circumference around the head at the level of the point just above the glabella anteriorly and the occipital protuberance posteriorly. At about 12-16 days of postnatal age when babies 
were found stable and feeding was advanced to at least $50 \mathrm{ml} / \mathrm{kg} /$ day with breast milk, base line investigations like CBC ( $\mathrm{Hb} \%, \mathrm{HCT})$, Reticulocyte count and Serum Ferritin level were done. Group-I (Control) (n-20) has received only oral $\mathrm{FeSO}_{4}(6 \mathrm{mg} /$ $\mathrm{kg} /$ day) \& folic acid $(1 \mathrm{mg} / \mathrm{kg} /$ day) up to 12 weeks. Group-II (Oral) (n-20) has received oral rhEPO 400IU added to breast milk three times a week for up to 2 weeks, total six dose with daily administration of oral $\mathrm{FeSO}_{4}(6 \mathrm{mg} / \mathrm{kg} /$ day $) \&$ folic acid $(1 \mathrm{mg} / \mathrm{kg} /$ day) up to 12 weeks. Group-III (Subcutaneous) (n-20) has received rhEPO $400 \mathrm{IU}$ subcutaneously in the anterior thigh three times a week for up to 2 weeks, total six dose with daily administration of oral $\mathrm{FeSO}_{4}(6 \mathrm{mg} / \mathrm{kg} /$ day)\&folic acid ( $1 \mathrm{mg} / \mathrm{kg} /$ day) up to 12 weeks.

Recombinant human Erythropoietin (rhEPO) was available as Injection Epoitin (1000 IU in $0.5 \mathrm{ml}$ )in a prefilled syringe manufactured by a local Pharmaceutical company (Incepta Pharmaceuticals Limited). It was diluted 10 times with normal saline\& calculated in drops for oral administration. S/C administration was done by the prefilled syringe without dilution. Iron and folic acid was given orally from day 1 of intervention in empty stomach before feeding. Care giver, nurses \& doctors were made aware of the adverse events that may happen. Adverse events such as feeding intolerance, necrotizing enterocolitis, circulatory instability, temperature instability, thrombocytopenia, leucopenia and others if any were recorded.

After discharge from the hospital parents were advised to attend the follow up clinic at 4weeks, 6 weeks and 12 weeks of age. During all visits anthropometric measurements like weight, length, OFC, side effects of drugs and hematological parameters like CBC ( $\mathrm{Hb} \%$, Hct.), Reticulocyte count (corrected with hematocrit) and Serum ferritin level were done. All the babies were exclusively breastfed after discharge. Any patient with $\mathrm{Hb}$ level of $<7 \mathrm{gm} / \mathrm{dl}$ found in any follow up, was evaluated and managed with blood transfusion and the number of which required in each group was recorded.

Blood samples were collected in two different test tubes, one containing EDTA for CBC, Reticulocyte count and other in plain test tube for Serum Ferritin level estimation. CBC ( $\mathrm{Hb} \%$, Hct.) was determined by photometric method using automated blood analyzer, ABX Pentra Dx 120. Reticulocyte count was done by (FAC) Fluorescent activated flow cell cytometer. Serum Ferritin estimation was done by ARCHITECT Ferritin assay using the reagent is ARCHITECT Ferritin Reagent Kit (7k59). All the investigations were done in the department of Biochemistry of BSMMMU,

Statistical Analysis: Data were processed and analyzed by using the Statistical Package for Social Sciences-20 (SPSS-20) software for Windows. To compare mean values between the groups one way ANOVA test was used. Chi square test was applied for categorical variables between the groups. Results were considered statistically significant at $p$ value $<0.05$.

\section{Results:}

Among the enrolled 60 newborns, after oral administration of iron, 4 babies had vomiting once or twice and abdomen seemed to be distended mildly. These problems were managed by keeping the oral iron off for one to two days. During the whole study period, 8 patients required blood transfusions (6 in control, 1 in oral and 1 in subcutaneous group), 5 patients developed feeding intolerance, and 3 patients had septicemia and DIC (Disseminated Intravascular Coagulation). One patient died, 1 patient denied further blood sampling after the first baseline investigations, 1 patient was dropped out after discharge keeping no further communication, so ultimately 57 patients completed the study. Among them $38(66 \%)$ were male and $19(34 \%)$ were female.

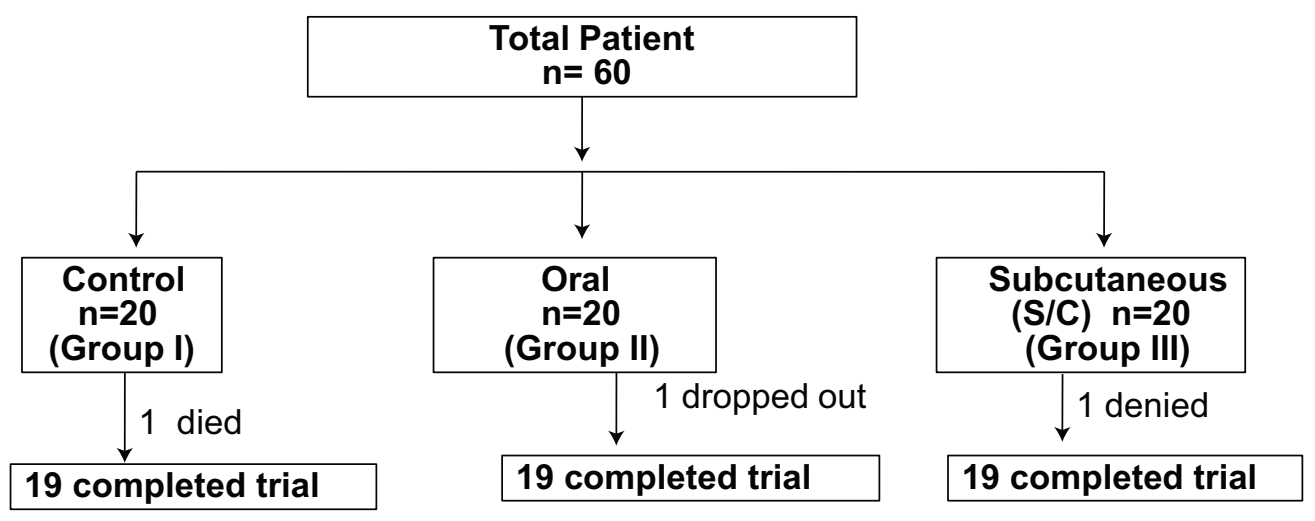

Fig.-1: Shows flow chart of the enrolled patients 
Table-I

Baseline characteristics of the babies at enrollment

\begin{tabular}{lcccc}
\hline Variables & $\begin{array}{c}\text { Group-1 } \\
(\text { Mean +SD })\end{array}$ & $\begin{array}{c}\text { Group-2 } \\
(\text { Mean +SD })\end{array}$ & $\begin{array}{c}\text { Group-3 } \\
(\text { Mean +SD })\end{array}$ & $\begin{array}{c}\text { P } \\
\text { Value }^{\#}\end{array}$ \\
\hline GA (weeks) & $30.95+1.46$ & $30.75+2.17$ & $31.55+1.39$ & .315 \\
BW $(g m)$ & $1222.63 \pm 131.86$ & $1235.50+144.50$ & $1280.50 \pm 142.25$ & .356 \\
PNA & $11.63+3.30$ & $12.9+1.27$ & $12.2+3.46$ & .466 \\
Weight at enrollment & $1105.26+136.60$ & $1140.50+140.61$ & $1187.89+134.60$ & .186 \\
\hline
\end{tabular}

\# one way ANOVA.

Table shows Gestational age at weeks (GA), Birth weight in grams (BW), postnatal age in days (PNA) and weight at enrollment were almost similar. No statistically significant difference was observed in the baseline parameters.

Table-II

Hematological parameters in three groups at 14 days and 28 days of age

\begin{tabular}{lccccc}
\hline Variables & Time of & $\begin{array}{c}\text { Control Group } \\
(\text { Mean+SD) }\end{array}$ & $\begin{array}{c}\text { Oral group } \\
(\text { Mean }+ \text { SD })\end{array}$ & $\begin{array}{c}\text { S/C group } \\
(\text { Mean }+ \text { SD })\end{array}$ & $\begin{array}{c}\mathrm{P} \\
\text { value }^{\#}\end{array}$ \\
\hline $\mathrm{HCT} \%$ & 14 days & $42.23 \pm 6.55$ & $42.27 \pm 5.36$ & $44.53 \pm 5.80$ & .398 \\
& 28 days & $37.67 \pm 7.01$ & $39.70 \pm 6.20$ & $39.83 \pm 5.31$ & .422 \\
$\mathrm{Hb}(\mathrm{gm} / \mathrm{dl})$ & 14 days & $14.07 \pm 2.23$ & $14.19 \pm 1.82$ & $14.81 \pm 1.93$ &. .484 \\
& 28 days & $12.62 \pm 2.07$ & $13.29 \pm 1.89$ & $13.30 \pm 1.75$ & .456 \\
Serum Ferritin & 14 days & $258.11 \pm 118.35$ & $294.18 \pm 75.28$ & $294.45 \pm 81.05$ & .393 \\
$(\mu \mathrm{gm} / \mathrm{L})$ & 28 days & $187.26 \pm 91.82$ & $181.56 \pm 61.50$ & $217.64 \pm 77.24$ & .315 \\
Reticulocyte \% & 14 days & $4.79 \pm 2.47$ & $4.65 \pm 0.969$ & $6.25 \pm 3.43$ & .102 \\
& 28 days & $5.69 \pm 2.60$ & $7.81 \pm 1.02$ & $7.11 \pm 3.39$ & .043 \\
\hline
\end{tabular}

\# one way ANOVA.

Hematological parameters(Hb level, Hct, Reticulocyte count and Serum ferritin level) in three groups at 14 days were similar but at 28 days of postnatal age there was a little increase in reticulocytosis in oral and subcutaneous group (p-0.043).

Table-III

Hematological parameters in three groups at $6^{\text {th }}$ weeks and $12^{\text {th }}$ weeks of age

\begin{tabular}{lccccc}
\hline Variables & Time & $\begin{array}{c}\text { Control Group } \\
\text { (Mean }+ \text { SD) }\end{array}$ & $\begin{array}{c}\text { Oral group } \\
\text { (Mean +SD) }\end{array}$ & $\begin{array}{c}\text { S/C group } \\
\text { (Mean +SD) }\end{array}$ & $\begin{array}{c}\mathrm{P} \\
\text { value }^{\#}\end{array}$ \\
\hline $\mathrm{HCT} \%$ & $6 \mathrm{wks}$ & $31.79 \pm 4.61$ & $33.78 \pm 3.01$ & $36.05 \pm 6.53$ & .036 \\
& $12 \mathrm{wks}$ & $34.11 \pm 2.03$ & $35.66 \pm 1.65$ & $36.38 \pm 3.97$ & .041 \\
$\mathrm{Hb}(\mathrm{gm} / \mathrm{dl})$ & $6 \mathrm{wks}$ & $10.56 \pm 1.54$ & $11.21 \pm 1.05$ & $12.05 \pm 2.26$ & .032 \\
& $12 \mathrm{wks}$ & $11.34 \pm 0.68$ & $11.88 \pm 0.54$ & $12.12 \pm 1.32$ & .034 \\
Serum Ferritin & $6 \mathrm{wks}$ & $106.28 \pm 49.27$ & $89.43 \pm 30.79$ & $124.76 \pm 44.28$ & .043 \\
$(\mu \mathrm{gm} / \mathrm{L})$ & $12 \mathrm{wks}$ & $96.50 \pm 44.32$ & $77.90 \pm 27.60$ & $111.10 \pm 41.53$ & .036 \\
Reticulocyte \% & $6 \mathrm{wks}$ & $7.11 \pm 2.61$ & $9.30 \pm 1.68$ & $8.50 \pm 3.42$ & .045 \\
& $12 \mathrm{wks}$ & $7.56 \pm 2.48$ & $9.85 \pm 1.50$ & $9.22 \pm 3.11$ & .017 \\
\hline
\end{tabular}

\#one way ANOVA

Hematological parameters in all three groups at 6 weeks and 12 weeks of age had statistically significant difference (p-values were <0.05). НCT\%, $\mathrm{Hb}(\mathrm{gm} / \mathrm{dl})$ was more in the subcutaneous group than Oral group and control group in order of value. Considering reticulocyte count and Serum Ferritin levels, there is increased erythropoiesis at 6 to 12 weeks of age after oral intervention with rhEPO in preterm low birth babies. 
Table-IV

Comparison of hematological parameters among the groups.

\begin{tabular}{|c|c|c|c|c|c|}
\hline Parameters & $\begin{array}{l}\text { Comparison in } \\
\text { between }\end{array}$ & $\begin{array}{l}\text { Age } 14 \text { days } \\
(P \text { value })^{\#}\end{array}$ & $\begin{array}{c}\text { Age } 28 \text { days } \\
(\mathrm{P} \text { value })^{\#}\end{array}$ & $\begin{array}{c}\text { Age 6weeks } \\
(P \text { value })^{\#}\end{array}$ & $\begin{array}{c}\text { Age } 12 \text { weeks } \\
(P \text { value })^{\#}\end{array}$ \\
\hline \multirow[t]{3}{*}{$\mathrm{Hb}(\mathrm{gm} / \mathrm{dl})$} & Control/Oral & 1.00 & 1.00 & .053 & .071 \\
\hline & Control/S/C & 1.00 & 1.00 & .058 & .067 \\
\hline & Oral/ S/C & 1.00 & 1.00 & .276 & .297 \\
\hline \multirow[t]{3}{*}{ Hct.\% } & Control/Oral & 1.00 & 1.00 & .055 & .069 \\
\hline & Control/ S/C & 1.00 & 1.00 & .052 & .061 \\
\hline & Oral/ S/C & 1.00 & 1.00 & .367 & .281 \\
\hline Serum & Control/Oral & .719 & 1.00 & .213 & .057 \\
\hline Ferritin & Control/S/C & .709 & 1.00 & .227 & $.048^{*}$ \\
\hline$(\mu \mathrm{gm} / \mathrm{L})$ & Oral/ S/C & 1.00 & 1.00 & .514 & .239 \\
\hline Reticulocyte & Control/Oral & .345 & $.041^{*}$ & $.039^{*}$ & $.047^{*}$ \\
\hline \multirow[t]{2}{*}{$\%$} & Control/ S/C & .231 & $.037^{*}$ & $.043^{*}$ & $.036^{*}$ \\
\hline & Oral/ S/C & .162 & .342 & 0.812 & 1.00 \\
\hline
\end{tabular}

\#one way ANOVA

Table shows comparisons of hematological parameters among the groups at 14 days, 28 days, 6 weeks and 12 weeks of age by their $p$ value was found significant difference between control vs oral and control vs subcutaneous group regarding ferritin level and reticulocyte count but no significant difference was observed between oral vs subcutaneous groups.

Administration of rhEPO through oral or subcutaneous route had almost similar efficacy.

Table-V

Blood transfusion required during study period

\begin{tabular}{lcccc}
\hline Blood Transfusionrequired & $\begin{array}{c}\text { Control Group } \\
(\mathrm{N}=19)\end{array}$ & $\begin{array}{c}\text { Oral Group } \\
(\mathrm{N}=19)\end{array}$ & $\begin{array}{c}\mathrm{S} / \mathrm{C} \text { Group } \\
(\mathrm{N}-19)\end{array}$ & $\begin{array}{c}\mathrm{P} \\
\text { value }^{\#}\end{array}$ \\
\hline Yes (8) & 6 & 1 & 1 & 0.026 \\
No (49) & 13 & 18 & 18 & \\
\hline
\end{tabular}

${ }^{\#} \chi^{2}$ test done

Table shows number of Blood transfusions required in all three groups during study period. Control group had more number of blood transfusions than intervention groups, which is statistically significant ( $p-0.026)$. Recombinant erythropoietin had a significant role in reduction of red cell transfusion in preterm low birth weight babies.

Table-VI

Adverse events observed during follow up

\begin{tabular}{lcccc}
\hline Adverse Events & Group-1 (n-19) & Group-2 (n-19) & Group-3 (n-19) & P-value ${ }^{\#}$ \\
\hline Apnea & 2 & 1 & 1 & .853 \\
Abdominal distention & 3 & 2 & 1 & .912 \\
Vomiting & 4 & 3 & 3 & .682 \\
Hyperkalemia & 1 & 0 & 1 & .359 \\
Lethargy & 5 & 4 & 3 & .956 \\
\hline
\end{tabular}

${ }^{\#} x^{2}$ test done

Adverse events in this study population were not significant statistically. 
Table-VII

Comparison of Weight between groups

\begin{tabular}{lcccc}
\hline ParametersWeight $(\mathrm{g})$ & $\begin{array}{c}\text { Group-1 (Control) } \\
\text { Mean } \pm \text { SD }\end{array}$ & $\begin{array}{c}\text { Group-2 (Oral) } \\
\text { Mean } \pm \text { SD }\end{array}$ & $\begin{array}{c}\text { Group-3(S/C) } \\
\text { Mean } \pm \text { SD }\end{array}$ & $\begin{array}{c}\text { P } \\
\text { Value }^{\#}\end{array}$ \\
\hline Enrollment (14days) & $1105.26+136.60$ & $1140.50+140.61$ & $1187.89+134.60$ & .186 \\
At 28 days & $1465.52 \pm 131.98$ & $1495.26 \pm 138.37$ & $1513.68 \pm 120.33$ & .521 \\
At 6 weeks & $1777.36 \pm 128.09$ & $1912.63 \pm 140.03$ & $1852.05 \pm 185.56$ & .031 \\
At 12 weeks & $2703.15 \pm 95.91$ & $2793.15 \pm 109.39$ & $2772.10 \pm 110.98$ & .029 \\
\hline
\end{tabular}

\#one way ANOVA

Mean weight in three groups were comparable at enrollment and at 28 days but at $6^{\text {th }}$ and $12^{\text {th }}$ week follow up weight difference is statistically significant. Significant weight gain has occurred in both oral and subcutaneous group.

\section{Discussion:}

Critically ill preterm infants experience daily phlebotomy losses within the first 1 to 2 weeks after birth which may equal $5-10 \%$ of their total blood volume. ${ }^{5}$ Such losses typically result in multiple RBC transfusions. This iatrogenic anaemia is commonly followed byAOP, necessitating additional transfusions. A limited capacity to increase the EPO concentration renders preterm infants less capable of compensating for either of this anaemia. Human recombinant erythropoietin (rhEPO) has been studied as an alternative to transfusions in preterm infants. ${ }^{18}$ The goal of therapy is to reduce the number of blood transfusions, exposure to different donors, and reducing the risk of transmission of CMV, Hepatitis B, HIV and other transfusion associated infection and also associated risk of retinopathy of prematurity and bronchopulmonary dysplasia. ${ }^{19,20}$ Parenteral administration of rhEPO has been shown to enhance erythropoesis and decreases the need for blood transfusion in preterm infants, its enteral administration provided some conflicting results. ${ }^{1,13,17}$ In this study we have assessed the efficacy of rhEPO through oral versus subcutaneous route over control.

A wide range of dosing schedule has been used by different authorities. ${ }^{2,11,21,22,23,24}$ In this study, preterm VLBW neonates received rhEPO $400 \mathrm{IU} / \mathrm{kg}$ either orally or subcutaneously, three times weekly for 2 weeks resulting in a total of $24001 \mathrm{U}$ in group-II Group III respectively.Group I did not received any rhEPO. All the infants in three groups were supplemented with iron and folic acid daily. Fifty seven neonates completed the study. Neonates of all groups were similar in gestational age, post natal age, birth weight, and weight at enrollment. At time of enrollment, majority of them were healthy but some presented with neonatal jaundice and infection. Baseline hematological values ( $\mathrm{Hb}$, Hct, reticulocyte count) were estimated and no significant differences were found between the three groups.

This study showed an significant increase in hematological values and reduction in number of transfusion and also higher weight gain during both $2^{\text {nd }}$ and $3^{\text {rd }}$ follow up in comparison to control group $(p<0.04)$. Baseline hematological values were within the normal levels but gradually reduced in both groups. Reduction of hemoglobin levels were more visible in control group than in other two groups $(p<0.05)$.

Carneilli et. al. were the first to evaluate the effect of EPO on preventing the AOP. ${ }^{25}$ They randomly assigned 22 premature infants with gestational aged" 32 weeks and birth weight d" $1.75 \mathrm{~kg}$, to receive rhEPO400 IU/kg three times a week plus iron $20 \mathrm{mg} /$ week intravenously from the second day of life (11 infants) or no rhEPO and no iron (11 infants). The two groups had similar birth weight and clinical variables. The treated infants required fewer blood transfusions and less volume of PRBC. Reticulocyte and hematocrit values were higher in the treated group. These data indicate that rhEPO, in combination with iron supplementation, is effective in reducing the need for blood transfusion in the premature infants. ${ }^{25}$ This finding is also in accordance with our finding. Both oral and subcutaneously supplemented with rhEPO group had higher $\mathrm{Hb} \%, \mathrm{HCT} \%$, better weight gain and lesser $\mathrm{PRBC}$ requirements.

Khatami et al. concluded that early rhEPO and iron administration stimulated erythropoiesis. ${ }^{26} \mathrm{~A}$ multi 
centric European study in VLBW infants showed no benefit in the first two weeks after birth. ${ }^{27}$ These findings are consistent with our study, where intervention and hematologic evaluation was done after two weeks of post natal age. Similar results were also found in other studies. ${ }^{2,22,24,28}$ In most studies, EPO staring soon after birth has shown a lack of useful effect, may be related to the effects of illness and transfusions on erythropoiesis, protein deficiency and high phlebotomy losses.

In this study, during follow up for6 weeks, number of neonates requiring blood transfusions were statistically significant, six (31.5\%) in control group and $1(5.26 \%)$ each in oral and S/C group. Transfusion requirement has been reported at $7-90 \%$ for premature infants. ${ }^{29}$ The results of this study were comparable with the previous studies. Most of the babies in this study had a stable clinical and cardio-respiratory condition. Soubasi et al. concluded that EPO administration reduces the need for transfusion in uncomplicated premature neonates, but not in complicated neonates requiring mechanical ventilation. ${ }^{30}$ Similarly Darveau et al. also concluded that rhEPO could not reduce the need for RBC transfusions in critically ill anemicpatient. ${ }^{31}$ No critically ill neonates were evaluated in this study.

Studies published to date have administered a wide range of oral or parenteral iron doses. In the present study, iron was administered orally at a dose of $6 \mathrm{mg} /$ $\mathrm{kg} /$ day to all infants in an effort to maximize the amount of iron available for erythropoietin. Doses of iron were adjusted weekly according to changes in body weight. Studies that evaluated EPO, reported limited erythropoiesis with inadequate iron supplementation ${ }^{32}$ Shannon et al. administered iron at $3 \mathrm{mg} / \mathrm{kg} /$ day for all infants who were tolerating full enteral feedings. ${ }^{31}$ Maier suggested that iron supplements in a dose of $2 \mathrm{mg} / \mathrm{kg} /$ day might have been inadequate for optimal erythropoiesis. ${ }^{33}$ Serum ferritin concentration presumably reflects adequate administration of iron and do not provide complete information about iron storage. ${ }^{33}$ As of Whitwhall study, serum iron level was not measured in the present study. ${ }^{34}$

No differences were noted regarding the side effects or morbidities between the groups. Some studies have reported hyperkalemia, convulsion, neutropenia, arthritis and exanthema but this did not occur in this study. ${ }^{9,24,32}$ Some studies also reported hypertension butblood pressure could not be measured in the present study due to lack of resource. ${ }^{32,34}$

There was no significant difference in weight between the groups during enrollment but a difference was found at 6 weeks and 12 weeks of follow up $(p<0.05)$. As high hemoglobin level and absence of anaemia has a profound role on tissue oxygenation, cellular growth and proliferation as well as metabolic function, so an increment of weight was found from enrolment to the $12^{\text {th }}$ week follow upin oral and S/C group respectively. This finding is consistent with a study done by Khatami et al. ${ }^{26}$

Many controversial questions regarding the use of rhEPO in attempts to either diminish the severity of or to treat AOP, still remain unanswered. Strauss stated that rhEPO has efficiency in stimulating erythropoiesis in preterm infants, but the success in elimination or marked reduction in the need for RBC transfusion has not been definitively demonstrated. ${ }^{35}$ But Turker et al. concluded that rhEPO combined with enteral iron is effective and safe in preventing AOP, and reduced transfusion needs. ${ }^{36}$

Cochrane Collaboration Review of 23studies with enrollment of 2074 preterm infants, revealed that parenteral early administration of EPO reduces the no of red blood cell transfusion, volume transfused, and the number exposure of donors. ${ }^{37}$ While parenteral rhEPO has been shown to enhance erythropoiesis and decrease the need for late blood transfusion in preterm infant, the effects of its oral administration provided conflicting results. The result of this study is discussed for evaluation of the effects of enteral rhEPO on erythropoiesis in stable preterm infants.

\section{Conclusion:}

Oral EPO is as good as subcutaneous use of EPO in stimulating erythropoesis, maintaining $\mathrm{HCT}$ and $\mathrm{Hb}$ at high level and is safe in preterm baby.

\section{Recommendation:}

Before routine use of oral rhEPO in prevention of anemia of prematurity further large scale, multi-center, randomized, controlled clinical trials are needed to validate its beneficial effects.

\section{Limitations of study:}

Single center study with a small sample size. Oral preference for use of parental preparation orally preparation was not available in our market, parenteral preparation was used orally. Phlebotomy losses were 
not measured, and serum iron and serum erythropoietin level could not be done.

\section{References:}

1. Ballin A, Bilker RA, ArbeL E, Davidovitz $Y$, Kohelelet D. Erythropoietin, given enterally, stimulates erythropoiesis in premature infants. Lancet 1999;353:1849. [10359412] [doi.org/ 10.1016/S0140-6736(99)01222-2]

2. Kacho MA, Zahed Pasha Y, Hajian K,Moradi S. The effect of human recombinant erythropoietin on prevention of anemia of prematurity. Iran J ped. 2007; 17 (3): 257-62.

3. Fuller, NJ, Bates CJ, Cole TH. Plasma folate levels in preterm infants with or without $1 \mathrm{mg}$ daily folate supplement. European journal of Pediatrics. 1992;151:48-50.

4. Stoll JB, Klligman RM. Overview of mortality and morbidity. In: Behrman RE, Killgman RM, Jenson HB editors. Nelson textbook of pediatrics.18 ed. WB Saunders: Philadelphia; 2008. p. 519-31.

5. Yasmeen BHN, Chowdhury MAKA, Hoque MM, Hossain MM, Jahan R, Akhtar S. Effect of short term recombinant human erythropoietin (rHEPO) therapy in the prevention of anemia of prematurity (AOP) in very low birth weight (VLBW) neonates, Bangladesh Med Res Counc Bull. 2012;38:119123.

6. Britton JR, Christensen RD. Entral administration of recombinant erythropoietin to preterm infant. JPerinatol.1995;15:281-3. [8558334]

7. Kling PJ, Sullivan TM, Roberts RA, Philipps AF, Koldovský O. Human milk as a potential Enteral source of erythropoietin. Pediatric Res. 1998; 43:216-21. [9475287] [doi.org/10.12 03/ 00006450-199802000-00010]

8. Bechensteen AG, Hage P, Halvorsen S. Erythropoietin protein and iron supplementation for the prevention of anemia of prematurity. Arch Dis Child 1993; 69: 645-53.

9. Ohls RK. The use of erythropoietin in neonates. Clinics in perinatology 2000;27:381-96.

10. Garcia MG, Hutson AD, Christensen RD. Effect of recombinant erythropoietin on late transfusions in the neonatal intensive care unit: A meta-analysis. J Perinatol. 2002;22:108-111.
11. Halperin DS, Wacker P, Locourt G. Effects of recombinant human erythropoietin in infants with the anemia of prematurity: A pilot study. J Pediatr. 1990;116:779-786.

12. Juul SE, Joyce AE, Zhao Y, Ledbetter DJ. Why is Erythropoietin present in human milk? Study of erythropoietin receptors on enterocytes of human and rat neonates. Pediatr Res 1999;46:263-8. [10473039] [doi.org/10.1203/ 00006450-199909000-00003]

13. Juul SE, Christensen RD. Absorption of eternal recombinant human erythropoietin by neonates. Ann.Pharmacother.2003;37:782-6. [12773061] [doi.org/10.1345/aph.1C428]

14. Juul SE, Zhao Y, Dame JB, Du Y, Hutson AD, Christensen RD. Origin and fate of erythroietin in human milk. Pediatr Res 2000; 48:660-7. [11044488] [doi.org/10.1203/00006450200011000-00018]

15. Krafft A, Breymann C, Huttner C, Huch R, Huch A. Erythropoetic quality of maternal milk. Lancet. 1993;354:778.

16. Kling PJ, Willeitner A, Dvorak B, Blohowiak SE. Enteral erythropoetin and iron stimulate erythropoesis in suckling rats. J Pediatr Gastroenterol Nutr. 2008;46(2):202-7. doi:10. 1097/MPG. [0b013e3181559e8b.]

17. Britton JR, Christensen RD. Enteral administration of recombinant erythropoietin to preterm infants. J Perinatol. 1995; 15: 281-283.

18. Robin K, Ohls MD, Richard A, Ehrenkranz MD, Linda L, Wright MD. Effects of Early Erythropoietin Therapy on the Transfusion Requirements of Preterm Infants Bellow 1250 Grams Birth Weight. A Multicenter Randomized Controlled Trial, Pediatrics. 2001;108(4): 934-942.

19. Franz AR, Pohlandt F. Red blood cell transfusion in extremely low birthweight infants under restrictive transfusion guidelines, Is exogenous erythropoietin necessary? Arch dis child fetal neonatal ed. 2001;84:F96-F100.

20. Reiter PD, Rosenberg AA, Valuck RJ. Factors associated with successful erythropoietin therapy in premature infants. Ann Pharmacotherapy. 2000; 34:433-439. 
21. Carneilli VP, Rio IR, Montini G. Iron supplementation enhances response to high doses of recombinant erythropoietin in preterm infants. Arch Dis Child Fetal Neonatal Ed. 1998;18:F44-48.

22. Meyer MP, Sharma E, Carsons M. Recombinant erythropoietin and blood transfusion in selected preterm infants. Arch Dis Child Fetal Neonatal Ed. 2003;88:F41-45.

23. Fujio T, Marutama K, Koizumi T. Oral iron supplementation in preterm infants treated with erythropoietin. Pediatr Int. 2004;46:635-39.

24. Arif B, Farhan, K. Recombinant human erythropoietin therapy in low-birth weight preterm infants: A prospective controlled study. Pediatr Int. 2005;47: 67-71.

25. Carneilli V, Montini G, Dariol R. Effect of high dose of human recombinant erythropoietin on the need for blood transfusion in preterm infant. $J$ Pediatr. 1992;121(1):98-102.

26. Khatami SF, Mouri G, Torkaman M. Effects of early human recombinant erythropoietin therapy on the transfusion in healthy preterm infants. Indian J of pediatrics. 2008;75:1227-1230.

27. Donato H, Vain N, Rendo P, Vivas N, Prudent L, Larguia M. Effects of early versus late administration of human recombinant erythropoietin on transfusion requirements in premature infants. Results of a randomized, placebo-controlled, multicenter trial. Pediatrics. 2000;105:1066-1072.

28. Ohls RK, Christensen RD. Recombinant erythropoietin compared with erythrocyte transfusion in the treatment of anemia of prematurity. J Pediatr. 1991; 119: 781-88.

29. Shannon KM, Keith JF, Mentzer WC. Recombinant human erythropoietin stimulates erythropoiesis and reduces erythrocyte transfusion in very low birth preterm infants. Pediatrics 1995; 95: 1-8.

30. Soubasi V, Kremenopulous G, Diamandi E. In which neonates does early recombinant human erythropoietin treatment prevent anaemia of prematurity? Results of a randomized controlled study. Pediatr Res. 1993; 36(1):1066-73.

31. Darveau M, Notebaert E, Denault AY, Belisle S. Recombinant Human Erythropoietin Use in Intensive Care. Ann Pharmacother. 2002; 36(6):1068-74.

32. Ohls R, Osborne KA Christesen RD. Efficacy and cost analysis of treating very low birth weight infants with erythropoietin during their first two weeks of life; a randomized placebo- controlled trial. J pediatr. 1995;126:421-6.

33. Maier RF, Obladen M,Scigalla P. The effect of Epoetin beta on the need for transfusion in very low birth weight infants. N Eng J Med. 1994; 330:1173-8.

34. Whitehall JS, Palote SK, Campbell S. Recombinant human erythropoietin in anaemia of prematurity. Indian J Pediatrics. 1999;36: 17-22.

35. Strauss RG. Controversies in the management of the anemia of prematurity using single-donor red blood cell transfusions and/or recombinant human erythropoietin. Trans Med Rev. 2006; 20(1): 34-44.

36. Turker G, Sarper N, Gokalp AS. The effect of early recombinant erythropoietin and enteral iron supplementation on blood transfusion in preterm infants. Am J Perinatal. 2005;22(8):449-55.

37. Ohlsson A, Aher SM. Early erythropoietin for preventing red blood cell transfusion in preterm and/ or low birth weight infants (Review). Cochrane Database Syst Rev. 2006;3: CD004863. 